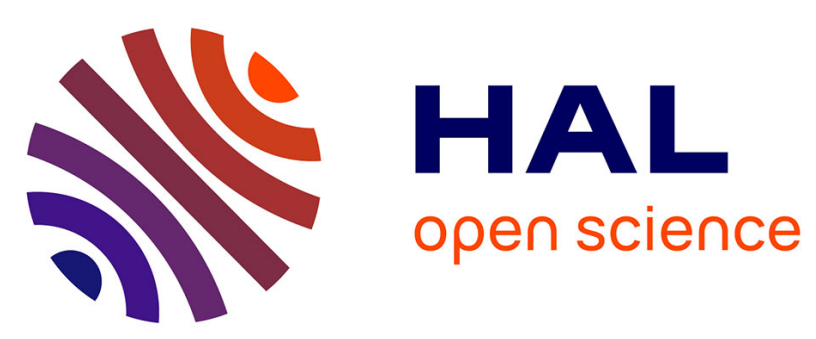

\title{
Exploring the Link between Visual Perception, Visual-Motor Integration, and Reading in Normal Developing and Impaired Children using DTVP-2
}

Stéphanie Bellocchi, Mathilde Muneaux, Andrea Huau, Yohana Lévêque, Marianne' Jover, Stéphanie Ducrot

\section{To cite this version:}

Stéphanie Bellocchi, Mathilde Muneaux, Andrea Huau, Yohana Lévêque, Marianne ' Jover, et al.. Exploring the Link between Visual Perception, Visual-Motor Integration, and Reading in Normal Developing and Impaired Children using DTVP-2. Dyslexia, 2017, 23 (3), pp.296 - 315. 10.1002/dys.1561 . hal-01772241

\section{HAL Id: hal-01772241 \\ https://hal.science/hal-01772241}

Submitted on 19 Jan 2022

HAL is a multi-disciplinary open access archive for the deposit and dissemination of scientific research documents, whether they are published or not. The documents may come from teaching and research institutions in France or abroad, or from public or private research centers.
L'archive ouverte pluridisciplinaire HAL, est destinée au dépôt et à la diffusion de documents scientifiques de niveau recherche, publiés ou non, émanant des établissements d'enseignement et de recherche français ou étrangers, des laboratoires publics ou privés.

$$
\text { Copyright }
$$


RUNNING HEAD: Visual perception and reading in normal developing and impaired children

Total number of words: 11230

Exploring the Link between Visual Perception, Visual-Motor Integration, and Reading in Normal Developing and Impaired Children using DTVP-2

\author{
Stéphanie Bellocchi ${ }^{1}$ \\ Mathilde Muneaux ${ }^{2}$ \\ Andréa Huau ${ }^{3}$ \\ Yohana Leveque $^{4}$ \\ Marianne Jover ${ }^{2,3}$ \\ Stéphanie Ducrot ${ }^{2}$
}

${ }^{1}$ Epsylon Research Unit EA 4556, University of Montpellier \& University Paul-Valéry Montpellier, 34199, Montpellier, France

${ }^{2}$ Aix Marseille Université, CNRS, LPL UMR 7309, 13100, Aix-en-Provence, France ${ }^{3}$ Aix Marseille Université, PSYCLE EA 3273, 13621, Aix-en-Provence, France

${ }^{4}$ Lyon Neuroscience Research Center, Brain Dynamics and Cognition Team \& Auditory Cognition and Psychoacoustics Team, CRNL, INSERM U1028, CNRS UMR5292, Lyon, F69000, France 


\begin{abstract}
Background. Reading is known to be primarily a linguistic task, and a large body of data has shown that there are many linguistic factors that affect word processing. However, to successfully decode written words, children also need to develop good visual-perception skills. Recent literature shows that motor skills also seem to be implicated in letter recognition and reading acquisition. Furthermore, developmental dyslexia is frequently associated with motor disorders, whereas children with developmental-coordination disorder exhibit poor reading outcomes.
\end{abstract}

Methods. The present paper contains three studies designed to determine the link between reading, visual perception, and visual-motor integration using DTVP-2. The first study tests how visual perception and visual-motor integration in kindergarten predict reading outcomes in Grade 1, in a group of typical developing children. The second one is aimed at finding out if these skills can be seen as clinical markers in a group of dyslexic children. The third study determine if visual-motor integration and motor-reduced visual perception can distinguish reading-impaired children according to whether they do or do not exhibit developmental-coordination disorder.

Results. The main results showed that phonological awareness, visual-motor integration, and motor-reduced visual perception predicted reading outcomes one year later. DTVP-2 demonstrated similarities and differences in these last two subcomponents between children with developmental dyslexia, developmental-coordination disorder, and both of these deficits.

Conclusions. The current work shows that the DTVP-2 battery is a suitable tool to investigate links between visual perception, visual-motor integration, and reading development, and to differentiate cognitive profiles of children with developmental disabilities, while dissociating reading impairment with or without motor impairment and highlighting commonalities between children who have comorbid or isolated disorders. 
Key words. Reading, visual perception, developmental dyslexia, developmentalcoordination disorder, comorbidity. 


\section{INTRODUCTION}

Academic success for children is usually based on the ability to read proficiently. Reading is essential for learning academic subjects and developing new cognitive skills. Consequently, there is a great deal of interest in the skills that affect reading ability and contribute to its improvement. Studying both the development of normal or impaired reading abilities and its predictors would help in developing teaching or remedial methods and identifying children at risk for later reading difficulty. The purpose of this paper was to evaluate the link between reading, visual perception, and visual-motor integration using a preexisting battery to test these skills (DTVP-2, Hammil, Pearson \& Voress, 1993).

\section{Relationship between phonological awareness and reading: A well-established fact}

The fact that speech abilities, especially phonological awareness, assist reading acquisition is now well-known, both in the scientific literature and in childcare centers. Phonological awareness refers to the ability to detect and manipulate individual speech sounds (Goswami \& Bryant, 1990). It has been argued that, since letters usually represent individual phonemes in alphabetic languages, a child needs to be aware of the phonemic segments in spoken words before going on to learn about their correspondences with letters or group of letters (Gough \& Hillinger, 1980; Mattingly, 1972). This ability would influence reading acquisition (Perfetti, Beck, Bell, \& Hughes, 1987; Torgesen, Wagner \& Rashotte, 1994) and could even predict word-reading development (Adams, 1990; Goswami \& Bryant, 1990; Kirby, Desrochers, Roth, \& Lai, 2008; Wagner \& Torgesen, 1987). Some studies have established a relationship between a deficit in phonological awareness and difficulties in children with specific reading impairment such as developmental dyslexia (DD; Adams, 1990; Goswami \& Bryant, 1990; Vellutino, Fletcher, Snowling, \& Scanlon 2004). DD is defined as a specific disability in learning to read and spell, in spite of normal intelligence, 
adequate instruction, socio-cultural opportunity, and no sensory defects in vision or hearing (WHO., 1992). Most dyslexic children currently benefit from remediation based on phonological training. This huge body of research on normal and pathological readers has provided numerous reliable tests or remedial intervention programs based on phonological awareness. However, beyond this well-documented relationship between phonological skills and learning to read, one should not ignore that there is much more to reading than phonological awareness.

\section{Implication of visual processing in reading: An important issue to consider}

Even if it is well known that to learn to read, children must develop good linguistic skills such as phonological awareness, phonological decoding, and orthographic processing, reading also requires a visual analysis of a uniquely ordered array of letters such as a familiar word and retrieval of the word representation from memory. The idea of the implication of visual skills in reading is not a recent one (Morgan, 1896), but it still remains an infrequently investigated issue. Recently, Kevan and Pammer (2009) demonstrated the implication of visual processes in the early stages of reading acquisition, using the spatial frequency doubling illusion (Kelly, 1966). The authors observed that sensitivity to this illusion, generated by rapid counter-phase modulation of two low-spatial-frequency gratings, and measured before a child begins explicit literacy instruction, can predict future reading skill in Grade 1. Franceschini and colleagues (2012) showed that visual-spatial attention in preschoolers is an important predictor of reading development. Children who had poor reading abilities during the first or second year of reading education made significantly more errors on a visual-search task and a spatial-cueing task than normal readers had when they were in kindergarten. Moreover, several studies tend to show that a number of dyslexics present a visual-processing deficit independently of phonological skills. For instance, the 
study by Valdois and her collaborators (2011) reported a case of a dyslexic child who exhibited dyslexia despite good phonological awareness. It has also been observed that some dyslexic children suffer from disturbances in contrast sensibility (Lovegrove, Bowling, Badcock, \& Blackwood, 1980), weak sensitivity in detecting coherent motion or forms (Cornelissen, Richardson, Mason, Fowler, \& Stein, 1995; Englund \& Palomares, 2012), or a visuo-attentional deficit (for a recent comprehensive review, see Bellocchi, Muneaux, Bastien-Toniazzo, \& Ducrot, 2013). Furthermore, according to Vidyasagar and Pammer (2010), attentional mechanisms controlled by the dorsal visual stream are necessary for serially scanning letters, and deficits in this process can have an impact in the visual processing of graphemes, their translation into phonemes, and the development of phonemic awareness.

That is, to successfully decode written words, children also need to develop good visual skills. In particular, it has been suggested that underlying the sublexical reading strategy there is a graphemic-selection mechanism based on the automatization of visuoattentional processes (e.g., Ruffino et al., 2010). To read new words by applying graphemeto-phoneme conversion rules, which is typical of the alphabetic stage, the child must be able to segment the fixated information. This means shifting from distributed attention to more focused attention. Rapid serial encoding enables normal grapheme/phoneme integration, that is, the ability to build a sublexical representation automatically. Rapid serial encoding treats letters as parts of a single object (the string) and allows for the formation of visual word forms. Moreover, to decode a word that is fixated in normal reading, the reader must be able to inhibit all surrounding letters and words. For such focusing operations, attentional processes must play an important role (Ducrot \& Grainger, 2007).

It has also been found that remediation based on training of visuo-attentional abilities improves reading abilities in dyslexic children (Launay \& Valdois, 2004; Lehtimäki \& Reilly, 2005). More recently, it was shown that an increase in the inter-letter spacing of a word and 
inter-word spacing of a text improves the speed and accuracy of reading by dyslexics (Zorzi et al., 2012).As a whole, the findings from dyslexics and typically developing readers therefore suggest a strong relationship between reading ability and visual processing.

\section{Relationship between motor skills and reading abilities: An emergent idea}

Recent literature reports that motor skills may also be implicated in reading acquisition. Indeed, gross motor skills are reported to have significant correlations with reading (Knight \& Rizzuto, 1993) and to facilitate children's academic abilities in reading, language, and mathematics (Son \& Meisels, 2006; Viholainen, Ahonen, Lyytinen, Cantell, Tolvanen, \& Lyytinen, 2006). Moreover, Son and Meseils (2006) observed that in early kindergarten, fine motor skills (especially visual motor skills and manual dexterity/hand-eye coordination) predict achievement in reading at the end of first grade. A study of two groups of preschool children who were learning letters either by handwriting or by typing strengthens this idea of the strong motor implication in reading (Longcamp, Zerbato-Poudou, \& Velay, 2005). These authors observed that training in handwriting gave rise to higher letterrecognition performance than training in typing. Some studies have established relationship between a motor-skill deficit and reading difficulties.

A brain lesion provoking the inability to write can also induce deficits in the visual identification of letters (Anderson, Damasio, \& Damasio, 1990). Additionally, dyslexics proved less successful than their peers at carrying on motor tasks (for a review, see Jover, Ducrot, Huau, Bellocchi, Brun-Hénin, \& Mancini, 2013). For instance, participants with DD demonstrated poor performance on the Movement Assessment Battery for Children (M-ABC, Henderson \& Sudgen, 1992; Iversen, Berg, Ellertsen, \& Tønnessen, 2005), pegboard tasks (Nicolson \& Fawcett, 1994), bead threading (Fawcett \& Nicolson, 1995), pointing (Velay, Daffaure, Giraud, \& Habib, 2002), and motor-learning tasks (Bennett, Romano, Howard, \& 
Howard, 2008). In graphomotor and handwriting tasks, children with DD exhibited more variation at the intra-individual level in writing a continuous repetitive alternated sequence of cursive letters (Borella, Chicherio, Re, Sensini, \& Cornoldi, 2011) or reproducing a character (Lam, Au, Leung, \& Li-Tsang, 2011). However, a handwriting deficit in DD is controversial because it is still unclear whether the children write more slowly due to spelling problems (Sumner, Connelly, \& Barnett, 2014), poorer motor control (Nicolson \& Fawcett, 2011), or both (Brun-Henin, Velay, Beecham, \& Cariou, 2013). Finally, epidemiological studies demonstrate a rate of comorbid diagnosis of developmental coordination disorder (DCD) in 16\% (Kaplan, Dewey, Crawford, Wilson, 2001) to 70\% (Iversen et al., 2005) of children with DD. DCD pertains to difficulty with various aspects of motor skills, from walking, overall coordination, and balance to fine abilities such as drawing or writing.

Interestingly, reading disability has been observed in 29\% (Gubbay, 1965) to $70 \%$ (O'Hare \& Khalid, 2002) of children diagnosed with DCD. Although the link between DCD and reading-developmental disorder is frequently reported in the scientific literature, little is known about the mechanisms of this comorbidity. Theories of atypical brain development (Gilger \& Kaplan, 2001) and procedural learning disorder (e.g. Nicolson \& Fawcett, 2007) have both proposed a partially common origin of DD and DCD, and more broadly, of all developmental disorders. Taken together, the research on typical and atypical development suggests that motor skills are involved in reading abilities.

To sum up, in addition to the well-documented importance of phonological skills in reading acquisition and dyslexia, visual perceptual and motor skills also appear as important factors in learning to read. Evaluating these skills is therefore an important challenge for dealing with reading impairment. Indeed, there is strong evidence suggesting that the problems experienced by elementary schoolers and older children in learning to read are related to the pre-literacy skills that they bring with them from preschool and kindergarten 
(Lonigan, 2006; Wagner, Torgesen, \& Rashotte, 1994). It therefore seems important to find a reliable and practical test that could assess both visual perception and motor skills. At the current time, most tools available to professionals are designed for the evaluation and remediation of child language problems, particularly difficulties related to the acquisition of meta-phonological skills (Frith, 1985; Goswami \& Bryant, 1990). Furthermore, there are very few tools today that focus on the assessment of visual perception for clinical purposes. Most of the findings suggesting a link between visual processing and reading are from studies implying specific experimental paradigms that rarely have a direct clinical application in terms of standardized diagnostic tools. However, it must be said that there exist some exceptions: the ADIVA battery developed by Ducrot and colleagues (2008) and the EVADYS test developed by Valdois, Guinet, and Embs (2014), both at which are diagnostic tools, and a battery for the early identification of visuo-attentional difficulties in prereaders currently being developed by Leibnitz and collaborators (2014).

In the past, different studies have investigated the relationship between visual perceptual skills - as assessed with tasks presented in the Developmental Test of Visual Perception (DTVP, Maslow, Frostig, Lefever, \& Whittlesey, 1964) - and reading comprehension, but they have failed to find a significant correlation between these two abilities. In the same vein, studies investigating the effects of visual-perception training on reading have strongly suggested that reading comprehension and visual perception, as measured and as trained, are relatively unrelated abilities (for a review, see Hammill, 1972). However, the studies developed in the 70's only took into account reading comprehension as the variable to predict, but not reading decoding. We assume that it could be useful to evaluate visual-perceptual and motor processing in order to better describe and understand dysfunctions or abilities in children with DD, particularly when it is associated with DCD. Furthermore, a battery assessing visual-perceptual and motor processing could help identify children at risk for reading impairment at an early age and consequently successfully plan 
educational intervention. As it is known, early assessment affording an as-accurate-aspossible indication of potential areas of difficulty constitutes a key in the efforts of schools and clinical services to meet and treat the specific problems faced by children with learning disabilities (Everatt, Smythe, Adams \& Ocampo, 2000).

\section{DTVP: a suitable battery to assess visual-perceptive and motor skills}

The DTVP could be suitable for the purposes mentioned above. The second edition, DTVP-2 ${ }^{1}$ (Hammill, Pearson, \& Voress, 1993), was developed to meet the need for a wellconstructed and effective psychometric test that can identify the visual-perceptual and motor performance of children. Version 2 of the DTVP can be administered to children between 4 and 10; 11 years of age, and gives a measure of visual cognitive functions, while distinguishing between visual-perceptual and visual-motor integration skills. It has eight subtests. Half of these subtests are designed to test visual-motor integration (eye-hand coordination, copying, spatial relationships, and visual-motor speed); they provide an index called the Visual-Motor Integration quotient (VMI). The other four subtests are designed to test perceptual skill free of motor control (position in space, figure-ground, visual closure, and form constancy), and furnish an index called Motor Reduced Visual Perception quotient (MRVP).

Beyond specifically assessing visual-perceptual and fine motor skills, the DTVP has been reported in the scientific literature as suited for studying normal and pathological development. The DTVP has been used to study learning in Chinese children (Cheung, Poon, Leung, \& Wong, 2005) or for evaluating the effects of handwriting assessment in typically developing children (Gruber, Meixner, Prosser, \& Sick, 2012). The DTVP allows one to examine repercussions of various kinds of neurological disorders such as postnatal acquired

\footnotetext{
${ }^{1}$ When our research started, the version 3 of DTVP (Hammill, Pearson, \& Voress, 2014), that is now published, was not available.
} 
herpes encephalitis (Valtonen, Dilks, \& McCloskey, 2008), periventricular leukomalacia (Fazzi, Bova, Uggetti, Signorini, Bianchi, Maraucci, Zoppello, \& Lanzi, 2004), benign childhood occipital seizures (Germanò et al., 2005), and childhood cerebral adrenoleukodystrophy (Kaga, Furushima, Inagaki, \& Nakamura, 2009). The DTVP can also be used to investigate some developmental diseases such as pervasive developmental disorders (Corden, Shilvers, \& Skuls, 2008) or DCD (Schoemaker et al., 2001). Bonifacci (2004) found a significant difference in visual-motor integration between children with high and low gross motor skills, in the absence of significant differences in perceptual skills or intellectual ability. This result suggests that DTVP-2 can identify the specific cognitive profile of children suffering from gross motor difficulties but with normal visuo-perceptual skills. The DTVP battery has been also used to assess visual perception and visual-motor integration in children with Attention Deficit Hyperactivity Disorder (ADHD). In particular, Jung and collaborators (2014) recently suggested that among children with ADHD, visual perception is lower in those children with comorbid sensory processing disorder (SPD). Thus, visual perception may be related to sensory processing, especially in the reactions of the vestibular and proprioceptive senses. Among the developmental disabilities, we can see that no visual-perceptual and visual-motor integration assessment has been done using the DTVP on children with dyslexia.

Finally, the DTVP assesses effectiveness of intervention programs in academic achievement and reading (Lahav, Apter, \& Ratzon, 2013; Ratzon, Lahav, Cohen-Hamsi, Metzger, Efraim, \& Bart, 2009). In conclusion, this battery therefore seems to be useful for testing visual-perceptual and motor skills in childhood.

\section{The present study}

The following three studies were run to find out whether the pre-existing DTVP-2 battery is a suitable tool for investigating links between visual perception, visual-motor 
integration, and reading development, and to distinguish between the different cognitive profiles of children with developmental disabilities (i.e. DD and DCD). First, we wanted to determine which, among phonological awareness, visual perception, and visual-motor integration assessed in typically developing kindergartners, are the best predictors of reading outcomes in first grade. Second, we aimed to see if these abilities can be regarded as clinical markers in a group of dyslexic children. Third, we wanted to test if general visual perception across the subcomponents of visual-motor integration and motor-reduced visual perception assessed by DTVP-2 can dissociate reading impairment with or without motor impairment (in particular DCD).

\section{STUDY 1}

\section{Do visual perception and visual-motor integration assessed in kindergarten predict} reading outcomes in first grade?

In the first study, we used a longitudinal design to find out if visual perception and visual-motor integration assessed with DTVP-2 in kindergarten would predict reading outcomes of children in first grade.

\section{Method}

Participants. A total of 36 children took part in this study (mean age in months: 64.2, $\mathrm{SD}=3.9$ months at the first assessment; $82.2, \mathrm{SD}=3.9$ months at the second assessment). They were all selected and recruited from mainstream schools in a city in southern France. They were native speakers of French and had normal or corrected-to-normal vision; none suffered from any neurological, psychiatric, or emotional disorders or were educationally disadvantaged. We excluded children who were considered by their teachers as either having specific learning deficits (i.e., children with poor reading skills) or behavioral difficulties (i.e., children who exhibited attentional or other behavioral problems in class). 
Material. Each participant received the following assessments:

(1) Visual perception skills using DTVP-2.As stated above, DTVP-2 contains a battery of eight subtests that measure different but interrelated visual-perceptual and visual-motor abilities. Four subtests measure visual-motor integration (VMI): (i) Eye-hand coordination, which requires children to draw a line within a straight broad band; (ii) Copying, in which children are shown simple figures and asked to draw them on a piece of paper; (iii) Spatial relations, which requires children to make a copy of shapes by connecting points arranged with regular distance; and (iv) Visual-motor speed, in which children trace very quickly a sign inside different geometrical shapes. The other four subtests measure motor-reduced visual perception (MRVP), as they require little or no motor skill: (i) Position in space, which requires children to select the exact figure from a series of similar but different figures. It involves discrimination of reversals and rotations of figures; (ii) Figure-ground, in which children are asked to find as many of the figures as they can on a page where the figures are hidden in a complex and confusing background; (iii) Visual closure, which requires children to select the exact figure from a series of figures that have been incompletely drawn; and (iv) Form constancy, in which children are shown a stimulus figure and asked to find it in a series of figures that vary on one or more discriminating features (i.e., size, position, or shade).

Participants' performance was assessed according to the scoring key provided in the test manual of DTVP-2 (Hammill, Pearson and Voress, 1993). Overall, DTVP-2 yields a general visual perception (GVP) quotient, which is a composite of the motor-reduced visual perception (MRVP) and visual-motor integration (VMI) quotients. Raw scores for each subtest are corrected for age in order to obtain a standard score. At the time of this study, no French standardization of DTVP-2 was available, which forced us to refer to the USA norms. This fact may constitute a limitation. However, since the test assesses nonverbal skills, we can assume that presumably no important differences appears between French and American children. The time required for this assessment was $30 \mathrm{~min}$ for each child. 
(2) Phonological awareness using two subtests of the French test the New Language Examination Battery (Chevrie-Muller \& Plaza, 2001). We administered the "Phoneme Identification" task, where the children were asked to identify the initial phoneme of 15 disyllabic words, ten with a vowel and five with a consonant (/v, l, p, r, s/) in initial position, for example /a/ in "ami" (friend). The experimenter gave two examples for each task, and for each item, recorded response accuracy ( 0 for erroneous and 1 for correct responses). We also administered the "Rhyme" task, in which the child hears two words and has to say if they have the same final sound, for example "poney" / "bonnet" ("pony" / "hat"), which in French have the same final sound /e/. Scoring was 0 for errors and 1 for correct responses. The time required for this assessment was around 15 min for each child.

(3) Reading outcomes using the "Alouette Test-R" (Lefavrais, 2005). The "Alouette Test-R" is commonly used in France to assess reading proficiency in terms of both word and non-word decoding and reading speed. The test is specifically designed to assess proficiency at rapidly switching between lexical and non-lexical processing during text reading. This test was developed to avoid the use of contextual information, known to be used as a compensatory strategy by poor readers and dyslexics. The text contains 265 words, ranging from common words to rarely used ones. Participants are instructed to read the text as fast and as accurately as possible. In this test, the score is based on fluency (number of words correctly read in 3 minutes) and accuracy (reading errors being taken into account). It also provides a reading level, expressed in months. The time required for this assessment was 5 min for each child.

Procedure. In this longitudinal study, two-step assessment procedure was run. At each testing step of the study, children were withdrawn from their classrooms. At Time 0 (middle of kindergarten) children were individually administered DTVP-2 and the "Phoneme 
Identification" and "Rhyme" tasks; one year and 4 months later, at Time 1 (end of Grade 1), the same children were individually administered the "Alouette Test-R".

The study was conducted in accordance with the Declaration of Helsinki (WHO, 2008), approved by the local Ethics Committee Review Board (Comité de Protection des Personnes [CPP] pour la recherche biomédicale, CNRS, France). The children's parents gave their written consent for participation.

\section{Results}

Table 1 shows the means and standard deviations of each standard composite measure of DTVP-2 (i.e. MRVP, VMI, and GVP), and of the "Phoneme Identification" and "Rhyme" tasks from the first assessment. These five measures were taken as predictors of reading abilities, assessed with the "Alouette Test-R", such as accuracy (number of words correctly read over the total number of words read), fluency (number of words correctly read in 5 minutes), and reading level. Means and standard deviations of the reading measures are also presented in Table 1. Statistical analyses were conducted using the SPSS $₫$ program, version 20.0 .

Insert Table 1 about here

A step-wise regression analysis was carried out to identify significant visuo-perceptual and phonological predictors of first grade reading outcomes. Separate analyses were run for each outcome variable measuring reading abilities (reading accuracy, fluency, and level). Thus, three regression analyses were run in all. 
Reading Accuracy. The analysis revealed that both phonological and visual-perceptual skills significantly predicted reading outcomes in Grade 1 . In particular, the Rhyme score ( $=.40, p<.05)$ and the VMI score $(\beta=.33, p<.05)$ were significant predictors of reading accuracy. These predictors accounted for about $31 \%$ of the variance in the test scores $\left[\left(\mathrm{R}^{2}=\right.\right.$ $\left..31) ; \mathrm{F}_{(1,35)}=8.9, p<.001\right]$.

Reading Fluency. Here the analysis revealed that only the Phoneme Identification score $(\beta=.50, p<.05)$ was a significant predictor of reading fluency at the end of Grade 1. This predictor accounted for about $22 \%$ of the variance in the test scores $\left[\left(\mathrm{R}^{2}=.22\right) ; \mathrm{F}_{(1,35)}=\right.$ $11.2, p<.05]$

Reading Level. The analysis revealed that both phonological and visual perceptual skills significantly predicted reading outcomes in Grade 1. In particular, the Phoneme Identification score $(\beta=.59, p<.001)$ and the MRVP score $(\beta=-.37, p<.05)$ were significant predictors of reading level. These predictors accounted for about $33 \%$ of the variance in the test scores $\left[\left(\mathrm{R}^{2}=.33\right) ; \mathrm{F}_{(1,35)}=9.5, p<.001\right]$.

\section{Discussion}

This longitudinal study showed, as is well documented in the literature, that phonological awareness predicts reading outcomes one year later. However, more interestingly, these results also showed that visual-perception skills contribute to predicting the development of reading abilities, which is in line with other studies (e.g. Son \& Meisels, 2006). In particular, motor-reduced visual perception, as well as the visual-motor integration subcomponent, assessed in kindergarten, predicted reading outcomes one year later. The better a child's motor-reduced visual perception and visual-motor integration skills are, the better his/her reading abilities will be. In other words, those two components both contributed to understanding skills involved in the development of reading, since they significantly increased the variance explained by the regression models. Moreover, the longitudinal 
research design used in this study controlled for the effects of reading experience: adopting this design, we can assume that visual-perceptual and visual-motor-integration abilities can be considered as predicting factors of reading development and not a consequence of reduced reading experience (Goswami, 2003; Goswami, 2014). It is useful to stress here that no child presented a pathological score in any of the tests used. The results are further discussed in the General discussion section of this manuscript.

\section{STUDY 2}

\section{Can visual perception and visual-motor integration be seen as clinical markers in dyslexic children?}

This second study was aimed at assessing visual perception and visual-motor integration using DTVP-2 in children with DD, as compared to typically developing children matched on chronological age or reading level.

\section{Method}

Participants. Sixty children participated in the experiment. They were divided into three groups: one of 20 dyslexics (DD) (mean age in months $=114.3 ; \mathrm{SD}=11.3$ ) and two control groups each composed of 20 typical developing readers, the first of which was matched on chronological age (CA) (mean age in months $=114.8 ; \mathrm{SD}=11.6)$ and the second of which was matched on reading level $(\mathrm{RL})$ (mean age in months $=83.3 ; \mathrm{SD}=5.8)$.

Dyslexic children were recruited and diagnosed at the La Timone University Hospital in Marseille, France. They all underwent a complete medical, psychological, neuropsychological, and cognitive assessment administered by an interdisciplinary team of psychologists, neurologists, and speech therapists. Criteria for inclusion in the sample were manifest reading deficits (at least two SDs below the normal level) on the "Alouette Test-R" 
(Lefavrais, 2005), an IQ level measured on the WISC-IV (French version by ECPA, 2005) within normal limits, and no visual or hearing deficits. They were excluded from the study if their oral language skills were in the pathological range or if they were diagnosed with ADHD. All participants were native speakers of French with normal or corrected-to-normal vision.

The participants in the control groups were recruited from an elementary school (Grade 1 through 5) in a city in southern France, according to their reading level (Grade 1 or 2) and chronological age (Grade 4 or 5) of the dyslexic children. They were all native speakers of French and had normal or corrected-to-normal vision; none suffered from any neurological, psychiatric, or emotional disorders or were educationally disadvantaged. The inclusion criteria were a normal reading level, an IQ within normal limits, and no visual or hearing deficits. We excluded children who were considered by their teachers as having either a specific learning deficit (i.e., children with poor reading abilities) or behavioral problems (i.e., children with attentional or other behavioral problems in class).

The dyslexics' and the normal readers' reading abilities were tested using the standardized French reading "Alouette Test-R" (Lefavrais, 2005). As we noted by post-hoc analyses, the mean reading level of the dyslexic children (mean=84.7 months; $\mathrm{SD}=7.3$ months) was significantly below the mean reading level of the chronological age matched group (mean=123.2 months; $\mathrm{SD}=26.2$ months ; $p<.001$ ). However, as expected, the mean reading level of the dyslexic children was not significantly different from that of the readinglevel matched children (mean=84.8 months; $\mathrm{SD}=4.6 ; p=\mathrm{n} . \mathrm{s})\left(\mathrm{ANOVA}\right.$; group effect: $\mathrm{F}_{(2,59)}=$ $38.9 ; p<.001)$.

Material. Each participant underwent DTVP-2 described in Study 1.

Procedure. All children were tested individually: dyslexics were tested at the hospital and normal readers, in their schools. The session lasted about 45 minutes. Parental permission 
was obtained before administering the tests. The study was conducted in accordance with the Declaration of Helsinki (WHO, 2008), approved by the local Ethics Committee Review Board (Comité de Protection des Personnes [CPP] pour la recherche biomédicale, CNRS, France).

\section{Results}

In order to compare developmental dyslexics' (DD) visual perception and visualmotor integration skills with normal readers' skills (chronological-age matched group or CA and reading-level matched group or RL), we ran a multivariate analysis of variance (MANOVA) on the standard scores of motor-reduced visual perception (MRVP), visualmotor integration (VMI) subcomponents, and the general visual-perception score (GVP), with group (3 levels: DD, CA, and RL) as a between-participants factor. Statistical analyses were conducted using the SPSS ${ }^{\circledR}$ program, version 20.0. Table 2 gives the means and standard deviations of the MRVP, VMI, and GVP standard scores for each group.

Insert Table 2 about here

The results indicated a significant group effect on all three indexes: GVP quotient $\left(\mathrm{F}_{(2,}\right.$ $\left.{ }_{59)}=23.9 ; p<.001, M S E=0.5\right), \operatorname{MRVP}\left(\mathrm{F}_{(2,59)}=11.7 ; p<.001, M S E=0.3\right)$, and VMI $\left(\mathrm{F}_{(2,}\right.$ 59) $=35.4 ; p<.001, M S E=0.5)$. The dyslexics' GVP scores were lower than the RL's scores $(p<.001$; Bonferroni post-hoc tests). The same result was found for MRVP $(p<.001$; Bonferroni post-hoc tests) and VMI ( $p<.001$; Bonferroni post-hoc tests). Likewise, comparisons between the DD and CA matched groups yielded the same trend. Dyslexics' GVP sores were lower than the CA's scores ( $p<.001$; Bonferroni post-hoc tests). Here again, 
significant differences emerged for MRVP $(p<.001$; Bonferroni post-hoc tests) and VMI $(p<$ .001; Bonferroni post-hoc tests). RL's and CA's did not differ significantly on GVP or MRVP, but RL's outperformed CA's on VMI $(p<.05)$.

Figures $1(\mathrm{~A}, \mathrm{~B}, \mathrm{C})$ present the dyslexics' and normal readers' performance on DTVP-2 based on standard scores.

Insert Figure $1(\mathrm{~A}, \mathrm{~B}, \mathrm{C})$ about here

\section{Discussion}

Dyslexic children exhibited lower visual-perception and visual-motor-integration skills as compared to chronological age, and more importantly, reading-level matched controls. Here, the dyslexics performed significantly less well than the RL controls, which means that, in the areas of visual perception and visual-motor integration, the dyslexics group exhibited a specific deficit and not a developmental delay (Goswami, 2003; Goswami, 2014). From a developmental perspective, this is an important result and suggests that the observed visual-perceptual and visual-motor difficulties are not simply a consequence of poor exposure to reading but a marked and basic disorder underlying DD. Keep in mind here that two (or more) standard deviations below the mean is considered as the cut-off point for defining a disability. In this respect, it is important to underline that, in our study, very few of the dyslexics' scores were more than two standard deviations below the mean, which corresponds here to scores under 70. In particular, this was the case for the MRVP component, where only three dyslexics (15\%) got 70 or below. However, the DTVP-2 manual (Hammill, Pearson \& Voress, 1993) states that scores less than one standard deviation (i.e. below 85) are suitable for identifying children with visual perception difficulties. As we can see in Figure 1, three 
dyslexics $(15 \%)$ had scores less than or equal to 85 on the VMI subcomponent. For the MRVP subcomponent, nine dyslexics (45\%) got scores less than or equal to 85 , and finally, seven $(35 \%)$ were in this range for the composite GVP score.

The results are further discussed in the General discussion section while taking into account the results obtained from the third study.

\section{STUDY 3}

\section{Can visual perception and visual-motor integration differentiate between dyslexic children with or without a developmental coordination disorder?}

In this third study, we compared visual perception and visual-motor integration, as assessed using DTVP-2, of a group of children with DD, a group with DCD, and a group with the both developmental disorders.

\section{Method}

Participants. In all, forty-seven children participated in the experiment. Participants were recruited and diagnosed at the La Timone University Hospital in Marseille, France. All underwent a complete medical, psychological, neuropsychological, and cognitive assessment administered by an interdisciplinary team of psychologists, neurologists, and speech therapists. All participants were native speakers of French with normal or corrected-to-normal vision. Four groups of participants were set up. (1) A group of 24 dyslexics (DD) (mean age in months $=121.9 ; \mathrm{SD}=13.9)$. Criteria for inclusion in the sample were manifest reading deficits (at least 2 SDs below the normal level) on the "Alouette Test-R" (Lefavrais, 2005), on IQ measured on the WISC-IV (French version by ECPA, 2005) within normal limits and no deficits in vision or hearing. Children whose oral language skills were in the pathological range or who were diagnosed with ADHD were excluded from the study. More importantly, 
we selected children without a developmental coordination disorder. (2) A group of 12 dyslexic children with DCD $(\mathrm{DD}+\mathrm{DCD})$ (mean age in months $=118.1 ; \mathrm{SD}=14.2)$. Regarding a potential reading deficit, criteria for inclusion in the sample were manifest reading deficits (at least 2 SDs below the normal level) on the "Alouette Test-R" (Lefavrais, 2005), an IQ measured on the WISC-IV (French version by ECPA, 2005) within normal limits, and no vision or hearing deficits. Children were identified as displaying DCD if they had a score below the 15 th percentile on the French version of the M-ABC (Soppelsa \& Albaret, 2004), an IQ measured on the WISC-IV (French version by ECPA, 2005) within normal limits, and no vision or hearing deficits. As above, for the dyslexic children, they were excluded from the study if their oral language skills were in the pathological range or they were diagnosed with ADHD. (3) A group composed of 11 children with DCD only (mean age in months $=116.4 ; \mathrm{SD}=14.8)$. We selected children who were diagnosed as DCD on the basis of the criteria listed above, i.e., score on the French version of the M-ABC (Soppelsa \& Albaret, 2004) below the 15th percentile, on IQ measured on the WISC-IV (French version by ECPA, 2005) within normal limits, and no vision or hearing deficits. We excluded children with oral language skills in the pathological range, children with ADHD, and children with DD or reading difficulties. Table 3 below gives the mean scores on reading level (measured on the "Alouette Test-R") and general motor performances (M-ABC).

Insert Table 3 about here

As expected, post-hoc analyses showed that the mean reading level of the dyslexic children was significantly lower than the DCD's mean reading level but was not lower than 
that of the DD+DCD children $(p<.001)$. Similarly, the dyslexic children's mean percentile on motor performance was significantly higher than those of the DCD and the DD+DCD children $(p<.001)$. The difference between DCD and DD+DCD children was not significant.

Material. Each participant was given DTVP-2 described in Study 1.

Procedure. All children were tested individually. The dyslexics were tested at the La Timone Hospital. The session lasted about 45 minutes. Parental permission was obtained before administering the tests. The study was conducted in accordance with the Declaration of Helsinki (WHO, 2008), approved by the local Ethics Committee Review Board (Comité de Protection des Personnes [CPP] pour la recherche biomédicale, CNRS, France).

\section{Results}

In order to compare the performance on visual perception and visual-motor integration of children with developmental disorders, we ran a multivariate analysis of variance (MANOVA) on the standard scores of motor-reduced visual perception (MRVP), visualmotor integration (VMI) subcomponents, and the general visual perception score (GVP), with group (3 levels: DD, DD+DCD, and DCD) as a between-participant factor. Figure 2 shows the means and standard deviations of the standard scores in each group. Statistical analyses were conducted using the SPSS ${ }^{\circledR}$ program, version 20.0.

Insert Figure 2 about here

The results indicated a significant group effect on the GVP quotient $\left(\mathrm{F}_{(2,45)}=9.9 ; p<\right.$ $.001, M S E=0.3), \operatorname{MRVP}\left(\mathrm{F}_{(2,45)}=4.1 ; p<.05, M S E=0.2\right)$ and $\operatorname{VMI}\left(\mathrm{F}_{(2,45)}=15.1 ; p<\right.$ 
$.001, M S E=0.4)$. With regard to the GVP quotient, group DD outperformed groups DD+DCD and DCD $(p<.05$ and $p<.001$, respectively; Bonferroni post-hoc test). No significant differences were found between groups DD+DCD and DCD. In particular, for the MRVP subcomponent, the DCD children's scores were significantly lower than the DD children's scores $(p<.05$; Bonferroni post-hoc test) but were not lower than those of the DD+DCD children. The DD and DD+DCD groups did not differ significantly. Finally, DD children outperformed DD+DCD and DCD children on theVMI subcomponent $(p<.05$ and $p$ $<.001$, respectively; Bonferroni post-hoc test). There were no significant differences between groups DD+DCD and DCD.

\section{Discussion}

The results of this third study showed that dyslexic children got higher scores on general visual perception than did dyslexics with DCD and children with a developmental disorder only. Regarding the subcomponents, DCD children got lower MRVP scores than dyslexics. Moreover, the children with DCD (associated or not with dyslexia) obtained lower VMI scores than the dyslexics did. These results suggest that the MRVP subcomponent can discriminate between isolated disorders, in particular between children with dyslexia only and children with DCD only. Also, the VMI subcomponent can discriminate between children who have DCD and children who do not. Thus, these two subcomponents of DTVP-2 can discriminate between different cognitive profiles. In other words, the presence of a motor disorder (associated or not with dyslexia) seems to be sufficient to negatively affect VMI. With respect to DCD, these results suggest that contrary to the findings obtained by Crawford and Dewey (2008), it is not the association of DCD and another neurodevelopmental disorder that determines the presence of deficits in visual perception, but rather the occurrence of DCD in itself. In short, the presence of a DCD (isolated or not) seems to affect general visual 
perception, as assessed by DTVP-2, by means of its two subcomponents, motor-reduced visual perception and visual-motor integration.

As in Study 2, we analyzed how many children had scores less than or equal to 70 or between 70 and 85 (given, as mentioned above, that according to the DTVP-2 manual one standard deviation is suitable for identifying children with visual-perception difficulties). We found that none of the dyslexic children had scores below 70 on DTVP-2 and only two dyslexics $(8.3 \%)$ had scores between 70 and 85 on GVP. Among the children with DD and DCD, five of them (41.7\%) had scores between 70 and 85 on GVP, six (50\%) had scores between 70 and 85 on MRVP and VMI. In sum, for group DCD, one child (9\%) and three children (27.3\%) had scores under 70 on GVP, MRVP, and VMI. Four children (36.4\%), one child (9\%), and three children (27.3\%) had scores between 70 and 85 on GVP, MRVP, and VMI.

\section{GENERAL DISCUSSION}

One of the main goals of the present study was to explore the clinical usefulness of DTVP-2 in: (1) exploring which among phonological, visual-perception, and visual-motor factors, are the best predictors in learning to read, (2) describing specific cognitive profiles among children with reading impairments (i.e. DD) in order to improve diagnostic assessment and, (3) describing specific cognitive profiles among DD (associated or not with DCD) and DCD children in order to improve the differential diagnosis of these two disorders. This third study was also aimed at determining whether is able to differentiate between DD children with and without DCD when controlling with more severe inclusion criteria. To the best of our knowledge, this is the first study investigating the validity of DTVP-2 for predicting reading outcomes. Furthermore, among developmentally disabled children, there are no 
studies assessing visual perception and visual-motor integration using the DTVP, not even on children with dyslexia.

First of all, this longitudinal study showed that performance on visual perception predicted reading outcomes one year later. In particular, it showed that beyond linguistic abilities such as vocabulary or phonological awareness (Catts, Fey, Zhang, \& Tomblin, 1999; Snow, 1985), motor-reduced visual perception as well as the visual-motor integration subcomponent, assessed in kindergarten, predict reading outcomes in first grade. The better a child's motor-reduced visual perception and visual-motor integration skills, the better his/her reading abilities. In other words, these two components contribute to our understanding of the skills involved in the development of reading, since they significantly increased the variance explained by the models tested here. These results confirm that, even through it is well known that to learn to read, children must develop good linguistic skills such as phonological awareness, phonological decoding, and orthographic processing (e.g. Goswami \& Bryant, 1990; Snowling, 2000; 2006; Vellutino et al., 2004; for a review, see also Kirby et al., 2008), children also need to develop good visual skills in order to be able to successfully decode written words. The longitudinal research design used in this study controlled for the effects of reading experience: by adopting this design, we can now assume that visual perception and visual-motor integration abilities are predictive factors of reading development, and not a consequence of limited reading experience (Goswami, 2003; Goswami, 2014).

More specifically, how can we explain the relationship between visual-motor skills and reading? As stated in the Introduction section, Sons and Meseils (2006) observed that fine motor skills in early kindergarten, especially visual-motor ones like manual dexterity and hand-eye-coordination, predict achievement in reading at the end of first grade. In this vein, the study of two groups of preschool children who were learning letters either by handwriting or by typing strengthened the idea of a substantial motor implication in reading (Longcamp, Zerbato-Poudou, \& Velay, 2005). In that study, the authors observed that handwriting training 
gave rise to higher letter recognition performance than typing training. The hypothesis that letters are learned through the matching of a visual configuration and movements was taken into account in interpreting these interesting results, which suggest that letters are not represented solely by their visual characteristics but more broadly on the basis of a multimodal representation in which one of the components is sensorimotor in nature. Accordingly, the results of our Study 1 can be interpreted by taking into account the hypothesis of the impact of visual-motor skills on reading acquisition, via their contribution to letter recognition (Longcamp et al., 2005).

From a clinical perspective, the results of this first study have important implications for clinical applications because they show that academic skills (i.e. reading) develop partly by interacting with visual perception and visual-motor skills. In practice, these results suggest that it would be useful to assess visual perception and visual-motor skills for developmental screening in kindergarten as one element of a larger battery. Indeed, DTVP-2 is capable of successfully identify children at risk for reading difficulties.

Sensory theories of DD suggest that the basis of this disorder is a deficit that is sensory in nature (e.g. Goswami, 2011; Ramus, 2004; Sperling, Lu, Manis, \& Seidenberg, 2006; Stein \& Walsh, 1997). The hypothesis that a sensorimotor component is involved in learning to read could explain the results obtained in our second study. We found that dyslexics showed lower motor-reduced visual-perception and visual-motor integration skills than normal readers. These findings are in line with the results of the other studies presented in the Introduction section of this paper, which showed that a number of dyslexics present a visualprocessing deficit and have more difficulty than their peers taking tests assessing visual-motor integration such as the pegboard test (Nicolson \& Fawcett, 1994), bead threading (Fawcett \& Nicolson, 1995), and pointing (Velay, Daffaure, Giraud, \& Habib, 2002)]. According to Ramus (2004), motor impairments and perceptual deficits can be viewed as an associated sensorimotor syndrome caused by an abnormal cytoarchitectonic structure in subcortical 
areas. This so-called nonspecific marker model states that the core cognitive symptoms of dyslexia (the phonological deficit) originate from abnormalities of neural migration located in left perisylvian areas involved in phonological processing. The associated sensory symptoms of dyslexia (i.e. visual, motor, or auditory) originate from subcortical abnormalities in (possibly magnocellular) sensory pathways, particularly the thalamus. Possibly, motor symptoms might arise from a further spread of disruption from the thalamus to the cerebellum (Stein \& Walsh, 1997).

Firstly, the results of our second study underline and confirm the importance of the motor subcomponent of visual perception in learning to read. Secondly, in line with one of the main aims of this research, the present results point out the clinical usefulness of DTVP-2 as a specific battery for evaluating visual-perceptual and motor skills in order to describe the abilities and disabilities of children that have already received a diagnosis of DD. The possibility of describing specific cognitive profiles in this population allow the clinician to improve diagnosis and consequently to plan an ad hoc remediation and intervention program. As we observed in Study 2, three dyslexics (15\%) in our group had scores less than or equal to 85 on the VMI subcomponent, nine (45\%) had scores less than or equal to 85 on the MRVP subcomponent, and finally, seven (35\%) were in that range on the GVP composite score. These profiles could be the manifestation of subclinical deficits or, in some cases, could be hidden deficits in the presence of a developmental disorder that has not been identified yet. Because the mean group values were in the normal range, it is difficult to conclude that there is a clear deficit in visual perception and visual-motor integration in children with DD and in children with both DD and DCD. However, the lower scores of children with DCD or with DD and DCD, but also children with DD express a global visual-processing weakness.

In principle, Ramus (2004) suggests that his nonspecific marker model might apply not only to dyslexia, but to any neurodevelopmental disorder with relatively specific cognitive symptoms (possibly arising from similar cortical abnormalities in different locations) and 
associated sensorimotor deficits. This hypothesis offers potential explanations for the frequent association of specific neurodevelopmental disorders and sensorimotor manifestations, heterogeneity within each disorder, and disorder comorbidity.

Within this theoretical framework, we will discuss the results of Study 3. Overall, the results of our third study showed that dyslexic children had higher scores on general visual perception compared to dyslexics with DCD and children with DCD only. With regard to the subcomponents, children with DCD got lower MRVP scores than dyslexics. Moreover, children with DCD (associated or not with dyslexia) obtained lower VMI scores than dyslexic children. These results suggest that the MRVP subcomponent can discriminate between isolated disorders, especially between children with dyslexia only and children with DCD only. The VMI subcomponent can discriminate between children who have DCD and children who do not. These two subcomponents of DTVP-2 can therefore discriminate different cognitive profiles. In other words, the presence of a motor disorder (associated or not with dyslexia) seems to be sufficient to negatively affect VMI. From the standpoint of DCD, these results suggest that contrary to Crawford and Dewey's (2008) findings it is not the association between DCD and another neurodevelopmental disorder that determines the presence of visual perception deficits but rather the occurrence of DCD in itself. In other words, the presence of a DCD (isolated or not) seems to affect general visual perception, assessed here by the two subcomponents of DTVP-2 (motor-reduced visual perception and visual-motor integration).

We thus can contend here that, among children with developmental disabilities, MRVP and VMI scores fall along a continuum between low and high performance. In particular, children with DD only outperformed children with DD+DCD, who outperformed children with DCD only. That is, children with DCD only seem to have more difficulty both in MRVP and VMI than the other groups. According to Kaplan's model (e.g. Gilger \& Kaplan, 2001; Kaplan, Wilson, Dewey, \& Crawford,1998), this last result shows that those 
two components turn out to be related when the severity of the impairment is great, perhaps as a manifestation of atypical brain development. Indeed, children with DCD only exhibited lower motor skills than children with DD and DCD, as we can see in Table 3. Taking into account the results of Study 2 showing that dyslexic children had lower MRVP skills than normal readers, Figure 3 summarizes these observations concerning the different cognitive profiles of children with developmental disorders.

Insert Figure 3 about here

At this point, it is important to underline, in line with the idea of MRVP and VMI continuums, that there are some commonalities between neurodevelopmental disorders, not just differences. In particular, our children with DD+DCD showed difficulties in VMI, like children with DCD only, but they did not have difficulty in MRVP as the children with DD only did. This hypothesis should be further explored because some studies have demonstrated a visuo-motor deficit in children with DD (i.e., Emam \& Kazens, 2014).

\section{CONCLUSIONS}

The current study showed that the DTVP-2 battery is a suitable tool for investigating links between visual perception, visual-motor integration, and reading development. It is also useful for differentiating between the cognitive profiles of children with developmental disabilities, while dissociating between reading impairment with or without motor impairment, and for highlighting commonalities between children who have comorbidity or isolated disorders. For these reasons it seems suitable to systematically use DTVP-2 in the assessment of learning disabilities. 


\section{Acknowledgements}

The authors are grateful to Mr. Pierre Blache, Inspector of French National EducationGarlaban (Aix-Marseille Academy, France) for allowing us to run this research in some of his mainstream elementary schools. We would also like to thank Claire Gaillard, Agnes Gaussuin and Laetitia Filippi for their precious help in collecting some of the data presented in this paper. Finally, we are very grateful to the children and their parents who agreed to take part in this research.

Support for this research was partly provided by a grant from the French National Research Agency (ANR)-DYSTAC-MAP.

\section{Correspondence}

Stéphanie Bellocchi

Department of Psychology

Epsylon Research Unit EA 4556

University Paul-Valéry Montpellier

Route de Mende

34199 Montpellier Cedex 5

France

e-mail: stephanie.bellocchi@univ-montp3.fr

Phone number: 0033 (0) 411757072 


\section{Key points}

- Reading is known to be primarily a linguistic task. However, to successfully decode written words, children also need to develop good visual perception skills.

- Recent literature shows that motor skills seem also to be implicated in letter recognition and reading acquisition.

- DD is frequently associated with motor disorders, while children with DCD show poor reading outcomes.

- In addition to phonological skills, we found that visual perception and visualmotor integration were important predictors of reading acquisition.

- Our findings suggest that visual perception and visual-motor integration, as assessed by DTVP-2, can differentiate cognitive profiles of children with developmental disabilities, by dissociating between reading impairment with or without motor impairment, and by highlighting commonalities between children who have comorbidity or isolated disorders. 


\section{References}

Adams, M.J. (1990). Beginning to Read: Thinking and Learning about Print. Cambridge, MA: MIT Press.

Anderson, S. W., Damasio, A. R., \& Damasio, H. (1990). Troubled letters but not numbers. Brain, 113, 749-766.

Bellocchi, S., Muneaux, M., Bastien-Toniazzo, M., \& Ducrot, S., (2013). I can read it in your eyes: What eye movements tell us about visuo-attentional processes in developmental dyslexia. Research in Developmental Disabilities, 34, 452-460.

Bennett, I. J., Romano, J. C., Howard Jr, J. H., \& Howard, D. V. (2008). Two forms of implicit learning in young adults with dyslexia. Annals of the New York Academy of Sciences, 1145(1), 184-198.

Bonifacci, P. (2004). Children with low motor ability have lower visual-motor integration ability but unaffected perceptual skills. Human Movement Science, 23, 157-68.

Borella, E., Chicherio, C., Re, A. M., Sensini, V., \& Cornoldi, C. (2011). Increased intraindividual variability is a marker of ADHD but also of dyslexia: A study on handwriting. Brain and cognition, 77(1), 33-39.

Brun-Henin, F., Velay, J. L., Beecham, Y., \& Cariou, S. (2013). Troubles d'écriture et dyslexie: revue théorique, aspects cliniques et approche expérimentale. Développements, 13(4), 4-28.

Catts, H. W., Fey, M. E., Zhang, X., \& Tomblin, J. B. (1999). Language basis of reading and reading disabilities: Evidence from a longitudinal investigation. Scientific Studies of Reading, 3(4), 331-361.

Cheung, P., Poon, M., Leung, M., \& Wong, R. (2005). The Developmental Test of Visual Perception-2 normative study on the visual-perceptual function for children in Hong Kong. Physical \& occupational therapy in pediatrics, 25(4), 29-43. http://dx.doi.org/10.1080/J006v25n04_03 
Chevrie-Muller, C., \& Plaza, M. (2001). Nouvelles épreuves pour l'examen du langage. Paris: Les Editions du Centre de Psychologie Appliquée.

Corden, B., Chilvers, R., Skuse, D. (2008). Avoidance of emotionally arousing stimuli predicts social-perceptual impairment in Asperger's syndrome. Neuropsychologia, 46 (1), $137-47$.

Cornelissen, P., Richardson, A., Mason, A., Fowler, S., and Stein, J. (1995). Contrast sensitivity and coherent motion detection measured at photopic luminance levels in dyslexics and controls. Vision Research 35, 1483-1494. doi: 10.1016/00426989(95)98728-R

Crawford, S.G., Dewey, D. (2008). Co-occurring disorders: a possible key to visual perceptual deficits in children with developmental coordination disorder? Human Movement Science, 27, 154-68. http://dx.doi.org/10.1016/j.humov.2007.09.002, 18192047.

Dewey, D., Kaplan, B. J., Crawford, S. G., \& Wilson, B. N. (2002). Developmental coordination disorder: Associated problems in attention, learning, and psychosocial adjustment. Human Movement Science, 21, 905-918.

Ducrot, S., \& Grainger, J. (2007). Deployment of spatial attention to words in central and peripheral vision. Perception \& Psychophysics, 69(4), 578-590.

Ducrot, S., Ghio, A., Michaël, G., Muneaux, M., Rauzy, S., \& Lété, B. (2008). The ADIVA (Aide au DIagnostic des déficits Visuo-Attentionnels chez l'enfant) software package. Unpublished Technical Report (69 p.), Aix-Marseille University.

Emam, M., \& Kazem, A. (2014). Visual motor integration in children with and without reading disabilities in Oman. Procedia-Social and Behavioral Sciences, 112, 548-556.

Englund, J. A., \& Palomares, M. (2012). The relationship of global form and motion detection to reading fluency. Vision research, 67, 14-21. 
Fawcett, A. J., \& Nicolson, R. I. (1995). Persistent deficits in motor skill of children with dyslexia. Journal of Motor Behavior, 27(3), 235-240.

Fazzi, E., Bova, S. M., Uggetti, C., Signorini, S. G., Bianchi, P. E., Maraucci, I., Zoppello, M., \& Lanzi, G. (2004). Visual-perceptual impairment in children with periventricular leukomalacia. Brain \& Development, 26, 506-512.

Franceschini, S., Gori, S., Ruffino, M., Pedrolli, K., \& Facoetti, A. (2012). A causal link between visual spatial attention and reading acquisition. Current Biology, 22, 814-819.

Frith, U. (1985). Beneath the surface of developmental dyslexia. In K. Patterson, J. Marshall \& M. Coltheart (Eds.), Surface dyslexia: Neuropsychological and cognitive studies of phonological reading. (pp. 301-330). London: Erlbaum.

Germano E., Gagliano, A., Magazu, A., et al.(2005). Benign epilepsy with occipital paroxysms: neuropsychological findings. Epilepsy Research, 64, 137-50.

Gilger, J. W., \& Kaplan, B. J. (2001). Atypical brain development: A conceptual framework for understanding developmental learning disabilities. Developmental Neuropsychology, $20,465-481$.

Goswami, U. (2003). Why theories about developmental dyslexia require developmental designs. Trends in Cognitive Sciences, 7 (12), 534-540.

Goswami, U. (2011). A temporal sampling framework for developmental dyslexia. Trends in Cognitive Science, 15, 3-10.

Goswami, U. (2014). Sensory theories of developmental dyslexia: Three challenges for research. Nature Reviews Neuroscience, 16,43-54, doi:10.1038/nrn3836.

Goswami, U. C., \& Bryant, P. (1990). Phonological skills and learning to read. New-York : Psychology Press.

Gough, P. B., \& Hillinger, M. L. (1980). Learning to read: An unnatural act. Annals of Dyslexia, 30(1), 179-196. 
Gruber, T., Meixner, B., Prosser, J. \& Sick, B. (2012). Handedness tests for preschool children: A novel approach based on graphics tablets and support vector machines. Applied Sof Computing, 12, 1390-1398.

Gubbay, S. S., Ellis, E., Walton, J. N., \& Court, S. D. M. (1965). Clumsy children a study of apraxic and agnosic defects in 21 children. Brain, 88(2), 295-312.

Hammill, D. (1972). Training visual processes. Journal of Learning Disabilities, 5 (10), 3946.

Hammill, D. D., Pearson, N. A., \& Voress, J. K. (1993). Developmental test of visual perception (2nd. ed). Austin, TX: Pro-Ed.

Hammill, D. D., Pearson, N. A., \& Voress, J. K. (2014). DTVP-3: Developmental Test of Visual Perception - Third Edition. Austin, TX: Pro-ED.

Henderson, S. E., \& Sugden, D. A. (1992). Movement Assessment Battery for Children. London: The Psychological Corporation.

Iversen, S., Berg, K., Ellertsen, B., \& Tønnessen, F. E. (2005). Motor coordination difficulties in a municipality group and in a clinical sample of poor readers. Dyslexia, 11(3), 217231.

Jover, M., Ducrot, S., Huau, A., Bellocchi, S., Brun-Hénin, F., \& Mancini, J. (2013). Les troubles moteurs chez les enfants dyslexiques : Revue de travaux et perspectives. Enfance, 4, 323-347.

Jung, H., Woo, Y.J., Kang, J.W., Choi, Y.W., \& Mi Kim, K. (2014). Visual Perception of ADHD Children with Sensory Processing Disorder. Psychiatry Investigation, 11 (2), 119-123.

Kaga, M., Furushima, W., Inagaki, M., \& Nakamura, M. (2009). Early neuropsychological signs of childhood Adrenoleukodystrophy. Brain \& Development, 31, 558-61. 
Kaplan, B. J., Dewey, D. M., Crawford, S. G., \& Wilson, B. N. (2001). The term comorbidity is of questionable value in reference to developmental disorders: Data and theory. Journal of Learning Disabilities, 34(6), 555-565.

Kaplan, B. J., Wilson, B. N., Dewey, D., \& Crawford, S. G. (1998). DCD may not be a discrete disorder. Human Movement Science, 17, 471-490.

Kelly, D. H. (1966). Frequency doubling in visual responses. JOSA, 56(11), 1628-1632.

Kevan, A., \& Pammer, K. (2009). Predicting early reading skills from pre-reading measures of dorsal stream functioning. Neuropsychologia, 47(14), 3174-3181.

Kirby, J. R., Desrochers, A., Roth, L., \& Lai, S. S. (2008). Longitudinal predictors of word reading development. Canadian Psychology/Psychologie canadienne, 49(2), 103.

Knight, D. \& Rizzuto, T. (1993). Relations for children in grades 2, 3, and 4 between balance skills and academic achievement. Perceptual \& Motor Skills, 76, 1296-1298.

Lahav, O., Apter, A., Ratzon, N. (2013). Psychological adjustment and levels of self-esteem in children with visual-motor integration difficulties influences the results of a randomized intervention trial. Research in Developmental Disabilities, 34, 56-64.

Lam, S. S., Au, R. K., Leung, H. W., \& Li-Tsang, C. W. (2011). Chinese handwriting performance of primary school children with dyslexia. Research in developmental disabilities, 32(5), 1745-1756.

Launay, L., \& Valdois, S. (2004). Evaluation et prise en charge cognitive de l'enfant dyslexique et/ou dysorthographique de surface. Apprentissage de la lecture et dyslexies développementales : de la théorie à la pratique, 209-232.

Lefavrais, P. (2005). Test de l'Alouette-R. Paris : ECPA.

Lehtimäki, T. M., \& Reilly, R. G. (2005). Improving eye movement control in young readers. Artificial Intelligence Review, 24(3-4), 477-488.

Leibnitz, L., Ducrot, S., Grainger, J., \& Muneaux, M. (2014). Une batterie informatisée de dépistage des difficultés visuo-attentionnelles à destination des enfants de maternelle. 
Poster presented at APPREC Conference - Learning Written Language: Diversity of languages, Uniqueness of disorders, Strasbourg, France.

Longcamp, M., Zerbato-Poudou, M.T., Velay, J.L. (2005). The influence of writing practice on letter recognition in preschool children: A comparison between handwriting and typing. Acta Psychologica 119 (1), 67-79.

Lonigan, C. J. (2006). Development, assessment, and promotion of preliteracy skills. Early Education and Development, 17(1), 91-114.

Lovegrove, W. J., Bowling, A., Badcock, D., \& Blackwood, M. (1980). Specific reading disability: differences in contrast sensitivity as a function of spatial frequency. Science, 210(4468), 439-440.

Maslow, P., Frostig, M., Lefever, D.W., Whittlesey, J. R. (1964). The Marianne Frostig developmental test of visual perception, Perceptual and Motor Skills, 19, 463-99.

Mattingly, I. G. (1972). Reading, the linguistic process, and linguistic awareness. In J. F. Kavanagh \& I. G. Mattingly (Eds.), Language by ear and by eye: The relationships between speech and reading.(pp. 133-147). Cambridge, MA: MIT Press.

Morgan, W. P. (1896). A case of congenital word blindness. British medical journal, 2(1871), 1378.

Nicolson, R. I., \& Fawcett, A. J. (1994). Comparison of deficits in cognitive and motor skills among children with dyslexia. Annals of Dyslexia, 44(1), 147-164.

Nicolson, R. I., \& Fawcett, A. J. (2007). Procedural learning difficulties: reuniting the developmental disorders? Trends in Neurosciences, 30(4), 135-141.

Nicolson, R. I., \& Fawcett, A. J. (2011). Dyslexia, dysgraphia, procedural learning and the cerebellum. Cortex, 47(1), 117-127.

O'Hare, A., \& Khalid, S. (2002). The association of abnormal cerebellar function in children with developmental coordination disorder and reading difficulties. Dyslexia, 8(4), 234248. 
Perfetti, C. A., Beck, I., Bell, L. C., \& Hughes, C. (1987). Phonemic knowledge and learning to read are reciprocal: A longitudinal study of first grade children. Merrill-Palmer Quarterly (1982-), 283-319.

Ramus, F. (2004). Neurobiology of dyslexia: A reinterpretation of the data. Trends in Neuroscience, 27, 720-726.

Ratzon, N. Z., Lahav, O., Cohen-Hamsi, S., Metzger, Y., Efraim, D., \& Bart, O. (2009). Comparing different short-term service delivery methods of visual-motor treatment for first grade students in mainstream schools. Research in Developmental Disabilities, 30(6), 1168-1176.

Ruffino, M., Trussardi, A. N., Gori, S., Finzi, A., Giovagnoli, S., Menghini, D., ... \& Facoetti, A. (2010). Attentional engagement deficits in dyslexic children. Neuropsychologia, 48(13), 3793-3801.

Schoemaker, M.M., van der Wees, M., Flapper, B., Verheij-Jansen, N., Scholten-Jaegers, S., Geuze, R.H. (2001). Perceptual skills of children with developmental coordination disorder. Human Movement Science, 20, 111-133.

Snow, C. E. (1985). Literacy and language relationships during the preschool years. Harvard Educational Review, 53(2), 165-189.

Snowling, M. J. (2006). Language skills and learning to read: The dyslexia spectrum. In M. J.

Snowling e J. Stackhouse (a cura di), Dyslexia- Speech and Language (pp 1-14).

Chichester (West Sussex): Whurr Publishers.

Snowling, M.J. (2000). Dyslexia. Oxford: Blackwell.

Son, S.-H., \& Meisels, S. J. (2006). The relationship of young children's motor skills to later reading and math achievement. Merill-Palmer Quarterly, 52, 755-778. http://dx.doi.org/10.1353/mpq.2006.0033.

Soppelsa, R., \& Albaret, J.-M. (2004). Manuel de la Batterie d'Evaluation du Mouvement chez l'Enfant (MABC). Paris: ECPA. 
Sperling, A. J., Lu, Z. L., Manis, F. R. \& Seidenberg, M. S. (2006). Deficits in perceptual noise exclusion in developmental dyslexia. Nature Neuroscience, 8, 862-863.

Stein, J. \& Walsh, V (1997). To see but not to read: the magnocellular theory of dyslexia. Trends in Neuroscience, 20, 147-152 (1997).

Sumner, E., Connelly, V., \& Barnett, A. L. (2014). The influence of spelling ability on handwriting production: Children with and without dyslexia. Journal of Experimental Psychology: Learning, Memory, and Cognition, 40(5), 1441.

Torgesen, J. K., Wagner, R. K., \& Rashotte, C. A. (1994). Longitudinal studies of phonological processing and reading. Journal of learning disabilities, 27, 276-286.

Valdois, S. Guinet, E., \& Embs, J.L. (2014). EVADYS : outil diagnostic des troubles de l'empan VA (EVADYS : a diagnostic tool for VA span assessment). Isbergues, France : Ortho-Edition.

Valdois, S., Bidet-Ildei, C., Lassus-Sangosse, D., Reilhac, C., N'guyen-Morel, M. A., Guinet, E., \& Orliaguet, J. P. (2011). A visual processing but no phonological disorder in a child with mixed dyslexia. Cortex, 47(10), 1197-1218.

Valtonen, J., Dilks, D.D., \& McCloskey, M. (2008). Cognitive representation of orientation: a case study. Cortex, 44, 1171-1187.

Velay, J. L., Daffaure, V., Giraud, K., \& Habib, M. (2002). Interhemispheric sensorimotor integration in pointing movements: a study on dyslexic adults. Neuropsychologia, 40(7), $827-834$.

Vellutino, F. R., Fletcher, J. M., Snowling, M. J., \& Scanlon, D. M. (2004). Specific reading disability (dyslexia): what have we learned in the past four decades?. Journal of Child Psychology and Psychiatry, 45(1), 2-40.

Vidyasagar, T. R., \& Pammer, K. (2010). Dyslexia: A deficit in visuo-spatial attention, not in phonological processing. Trends in Cognitive Science, 14, 57-63. 
Viholainen, H., Ahonen, T., Lyytinen, P., Cantell, M., Tolvanen, A., \& Lyytinen, H. (2006). Early motor development and later language and reading skills in children at risk of familial dyslexia. Developmental Medicine \& Child Neurology, 48(05), 367-373.

Wagner, R. K., \& Torgesen, J. K. (1987). The nature of phonological processing and its causal role in the acquisition of reading skills. Psychological bulletin, 101(2), 192.

Wagner, R.K., Torgesen, J.K., \& Rashotte, C.A. (1994). Development of reading-related phonological processing abilities : New evidence of bidirectional causality from latent variable longitudinal study. Developmental Psychology, 30, 73-87.

Wechsler, D. (2005). Echelle d'Intelligence pour Enfants et Adolescents, 4ème édition. Paris: ECPA.

World Health Organisation (1992). The ICD-10 classification of mental and behavioural disorders. Clinical descriptions and diagnostic guidelines. Geneva: WHO..

World Health Organisation (2008). 59th General Assembly. In: Association WM, editor. Seoul, Korea: WHO.

Zorzi, M., Barbiero, C., Facoetti, A., Lonciari, I., Carrozzi, M., Montico, M., Bravar, L., George, F., Pech-Georgel , C., \& Ziegler, J.C. (2012). Extra-large letter spacing improves reading in dyslexia. Proceedings of the National Academy of Science, doi: 10.1073/pnas.1205566109. 
Table 1. Means and standard deviations of all variables included in the regression analyses: DTVP-2 composite measures (MRVP, VMI, and GVP), Phoneme Identification and Rhyme performance (z-scores) assessed in kindergarten, and reading skills ( $z$-scores) assessed in Grade 1.

\begin{tabular}{lcc} 
& Kindergarten & Grade 1 \\
\cline { 2 - 3 } & mean $(S D)$ & mean $(S D)$ \\
\hline MRVP (std. score) & $100.5(10.6)$ & - \\
VMI (std. score) & $113.6(14.7)$ & - \\
GVP (std. score) & $107.1(10.9)$ & - \\
Phoneme Identification (z-score) & $-0.1(1.1)$ & - \\
Rhyme (z-score) & $0.3(1.1)$ & \\
Reading Accuracy (z-score) & - & $0.2(1.1)$ \\
Reading Fluency (z score) & - & $0.8(1.2)$ \\
Reading Level (months) & - & $86.2(5.6)$ \\
Chronological age (months) & $64.23(3.9)$ & $82.2(3.9)$ \\
\hline
\end{tabular}


Table 2. Mean scores and standard deviations of the dyslexics (DD), the reading-level matched group (RL), and the chronological-age matched group (CA) on the DTVP-2 composite measures (MRVP, VMI, and GVP) (standard scores).

\begin{tabular}{lccc} 
& DD & RL & CA \\
& $(\mathrm{n}=20)$ & $(\mathrm{n}=20)$ & $(\mathrm{n}=20)$ \\
& & & \\
\cline { 2 - 4 } & mean $(S D)$ & mean $(S D)$ & mean $(S D)$ \\
\hline MRP (std. score) & $88.3(14.5)$ & $109.2(14.4)$ & $105.1(14.5)$ \\
VMI (std. score) & $96.4(10.1)$ & $123.6(10.0)$ & $114.0(10.9)$ \\
GVP (std. score) & $91.9(10.9)$ & $117.0(12.1)$ & $109.7(12.2)$ \\
\hline
\end{tabular}


Table 3. Participants' mean scores (standard deviations) on the "Alouette Test-R" and M$\mathrm{ABC}$.

$\mathrm{DD}(\mathrm{n}=24) \quad \mathrm{DD}+\mathrm{DCD}(\mathrm{n}=12) \quad \mathrm{DCD}(\mathrm{n}=11)$

\begin{tabular}{llll}
\hline mean $(S D)$ & mean $(S D)$ & mean $(S D)$ & MANOVA
\end{tabular}

Chronological age

(months)

$121.9(13.9) \quad 118.1(14.2) \quad 116.6(14.8)$

Alouette Test-R

(reading level/

$89.3(6.6)$

$89.7(8.6)$

$115.0(27.4) \quad p<.001$

months)

$\mathrm{M}-\mathrm{ABC}$

(percentiles)

Note: $\mathrm{DD}=$ children with $\mathrm{DD}$ only; $\mathrm{DD}+\mathrm{DCD}=$ children with $\mathrm{DD}$ and developmental coordination disorder; $\mathrm{DCD}=$ children with $\mathrm{DCD}$ only. 
Figure 1 (A,B,C). Dyslexics' and normal readers' performance on DTVP-2 (MRVP, VMI, and GVP components). The results are based on standard scores.

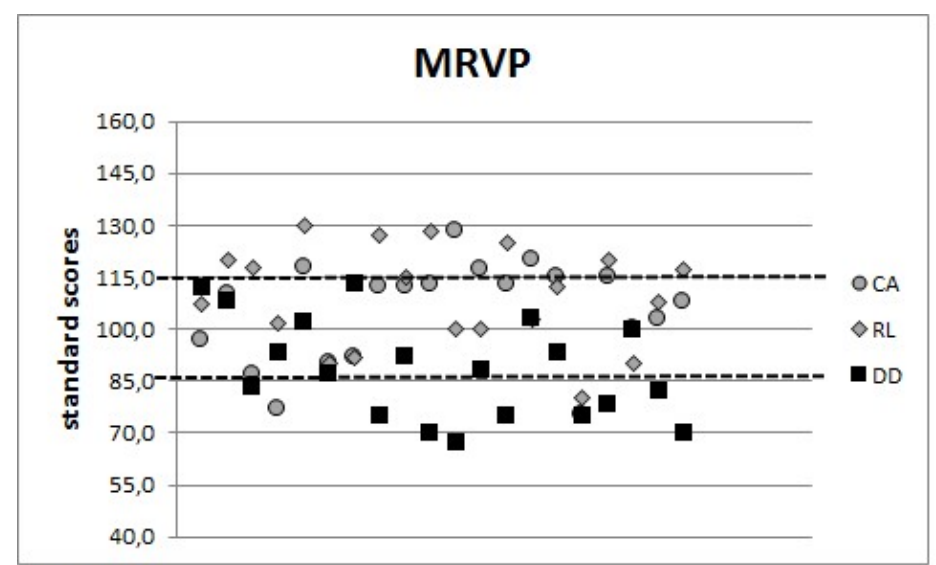

Figure 1.A

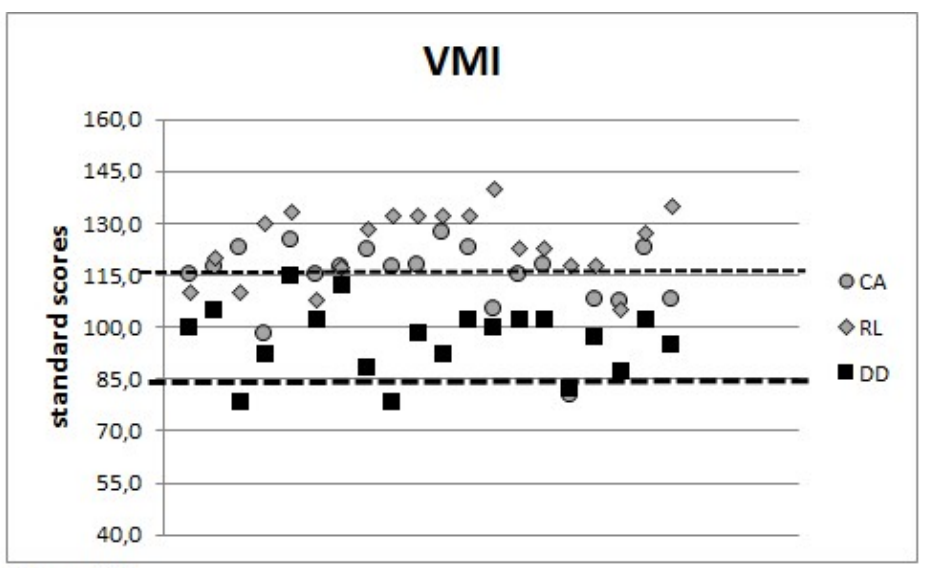

Figure 1.B



Figure 1.C

Note $. M R V P=$ motor-reduced visual perception $. \mathrm{VMI}=$ visual-motor integration $. \mathrm{GVP}=$ general visual perception. $\mathrm{CA}=$ chronological-age matched group. $\mathrm{RL}=$ reading-level matched group. $\mathrm{DD}=$ dyslexics. 
Figure 2. DD, DD+DCD and DCD children's standard scores on DTVP-2 (MRVP, VMI, and GVP components) (error bars indicate standard deviations).

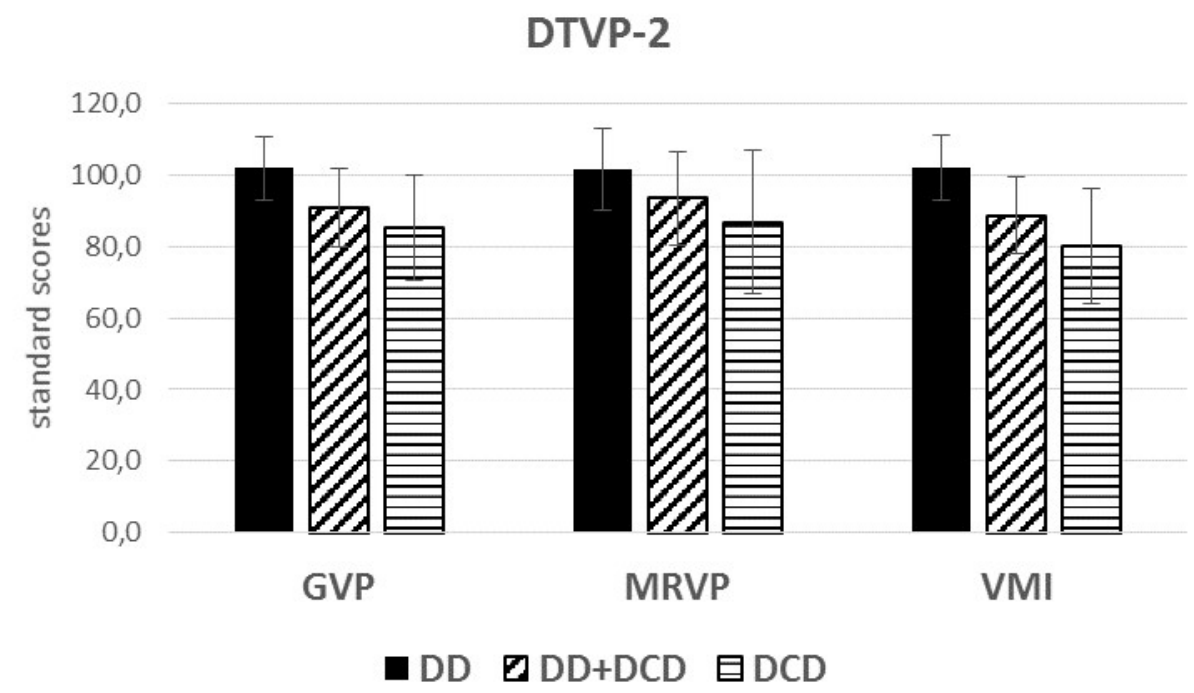

Note. $\mathrm{MRVP}=$ motor-reduced visual perception. $\mathrm{VMI}=$ visual-motor integration. $\mathrm{GVP}=$ general visual perception. $\mathrm{DD}=$ children with $\mathrm{DD}$ only. $\mathrm{DD}+\mathrm{DCD}=$ children with $\mathrm{DD}$ and developmental coordination disorder. $\mathrm{DCD}=$ children with $\mathrm{DCD}$ only. 
Figure 3. A two-dimensional model of the relationship between DD and DCD.

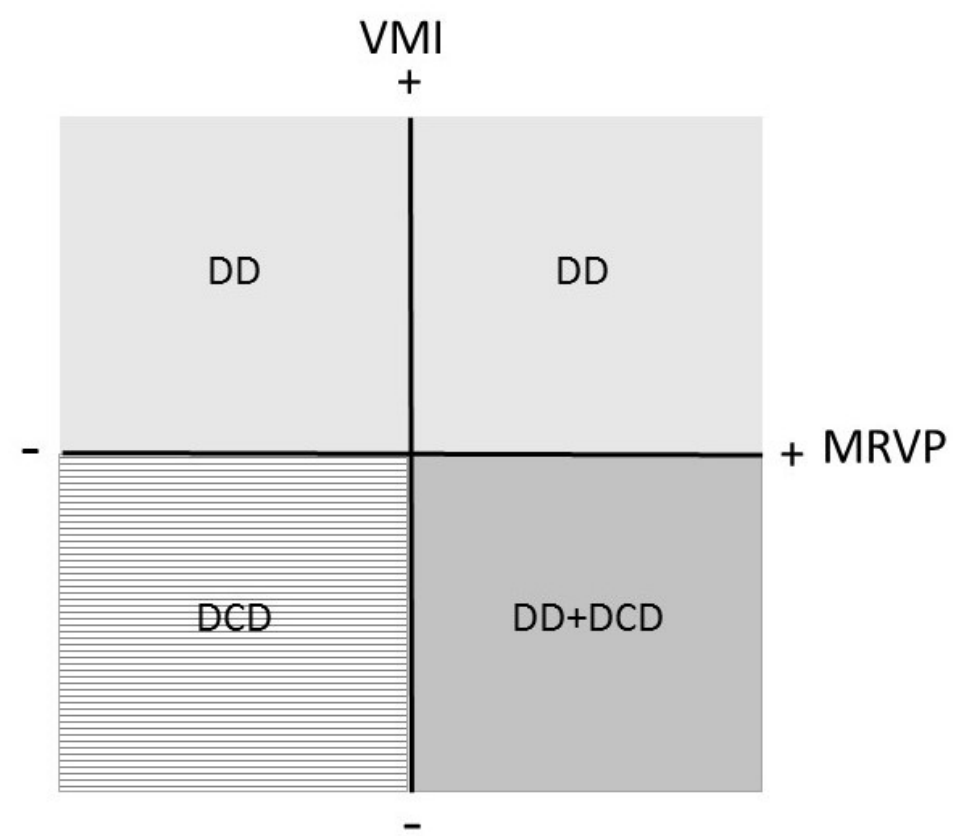

